\title{
Production and Evaluation of Anti-Mouse Polyclonal Antibody Against Enterotoxin B of Staphylococcus Aurous
}

\author{
Zeinab Najmi ${ }^{1,2}$, Soheil Ghasemi ${ }^{1}$, Rohollah Ghalandari ${ }^{3}$, Fattah Sotoudehnejad Nematalahi ${ }^{\text {* }}$ \\ ${ }^{1}$ Department of Biology, School of Basic Sciences, Science and Research Branch, Islamic Azad University, Tehran, Iran \\ ${ }^{2}$ Shefa Neuroscience Research Center, Khatam Alanbia Hospital, Tehran, Iran \\ ${ }^{3}$ Faculty of Chemistry and Chemical Engineering, Malek Ashtar University, Tehran, Iran
}

\begin{tabular}{|ccc} 
& Article Info: & \\
Received: 30 Sep 2019 & Revised: 13 Nov 2019 & Accepted: 20 Nov 2019
\end{tabular}

\section{A BSTRACT}

Introduction: Staphylococcus aureus is an important microorganism that causes the development of various diseases in humans by secretion of factors that are known as supraantigen of staphylococci. Enterotoxin B of Staphylococcus aureus is a bacterial antigen responsible for food poisoning in humans. To produce the corresponding polyclonal antibody, an antigen is injected into a susceptible animal and the serum of antibody content is extracted. Bacterial superantigens are potent $\mathrm{T}$ cell activators that can have acute or chronic effects on the central nervous system. This study aimed to develop a mouse polyclonal antibody againstenterotoxin B of Staphylococcus aureus. Materials and Methods: The Bradford method was used to determine protein concentration. For evaluation and identification of the antigen, the samples were transferred onto a nitrocellulose membrane by SDS-PAEG gel and analyzed by western blot analysis. Mice immunization was performed at intervals of zero, two, and four weeks using intraperitoneal injection. Antibody titer was measured in antisera isolated from the animal by the ELISA method. Results: Different concentrations of protein $(0-32 \mu \mathrm{g})$ with different adsorption were calculated with the formula $\mathrm{y}=0.0279 \mathrm{x}$ +0.1222 . There was no excess protein in the acrylamide gel. In the western blot analysis, the resulting bands represent complete conformance with the standard sample and are free from any unwanted protein. The results of the ELISA test were significant for the secretion of the second time at $\mathrm{p}<0.05$. In the double diffusion test, there was a bond between the control and the antigen. Conclusion: Prepared toxoid has completely lost its fecundity and therefore could be used to immunize and produce polyclonal antibodies against enterotoxin B of Staphylococci.

Key words:

1. Staphylococcus

2. Antibodies

3. Central Nervous System

*Corresponding Author: Fattah Sotoudehnejad Nematalahi

E-mail: fattah212@gmail.com 
توليد و بررسى آنتىبادى :للى كلونال موشى عليه انتروتوكسين B استافيلوكوكوس اورئوس

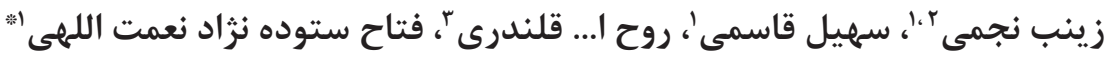 \\ اكروه زيست شناسى، دانشكده علوم پايه، واحد علوم و تحقيقات دانشعاه آزاد اسلامى، تهران، ايران \\ 'مركز تحقيقات علوم اعصاب شفا، بيمارستان خاتمالانبياء، تهران، ايران \\ 'دانشكده شيمى و مهندسى شيمى، دانشعاه مالك اشتر، تهران، ايران
}

اطلاعات مقاله:

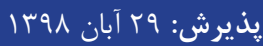

اصلاحيه: rr آبان

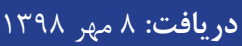

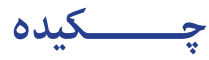

مقدمه: استافيلوكوك اورئوس يك ميكرواركانيسم مهمم است كه با ترشح فاكتورهايى كه بهعنوان سوير

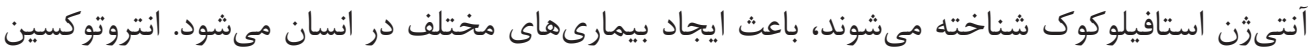

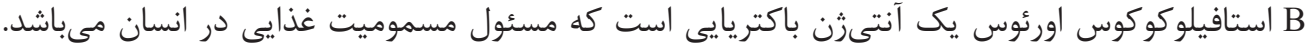

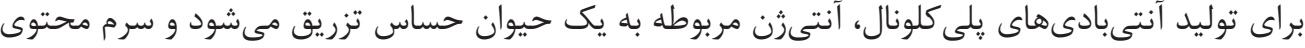

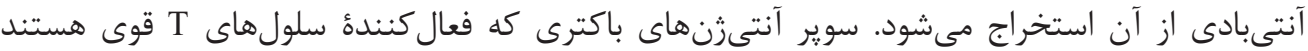

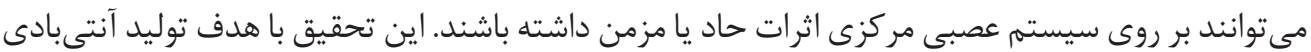

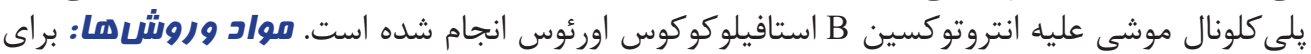

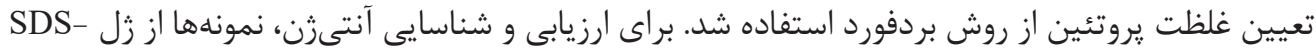

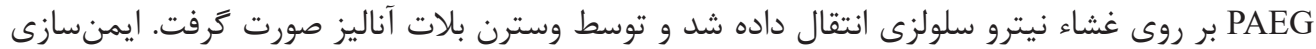

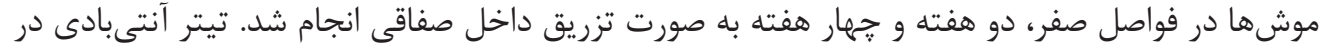

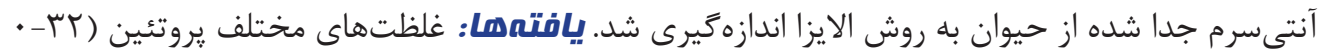

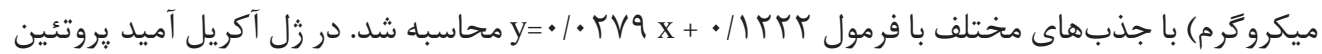

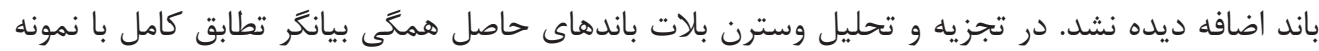

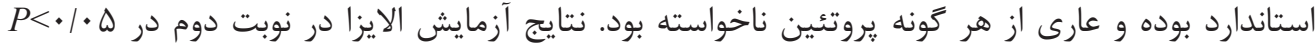

كليد وازهها: 1. r. r. آنتىبادى

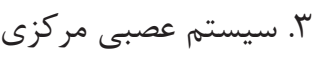

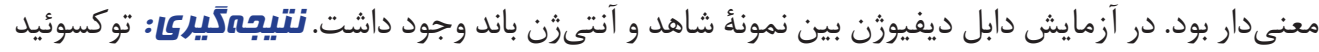

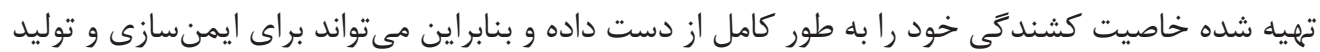

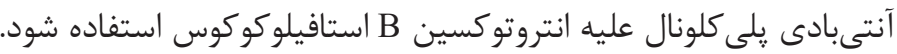

" نويسنده مسئول: فتاح ستوده نزاد نعمت اللهى آدرس الكترونيكى: fattah212@gmail.com 


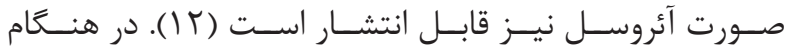

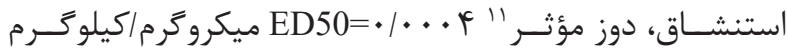

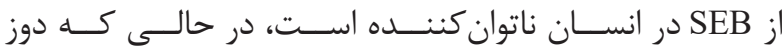

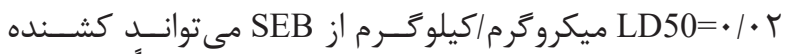

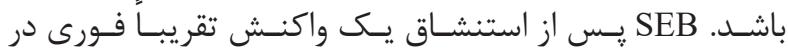

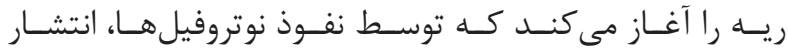

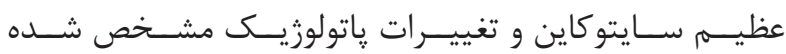

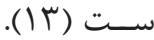

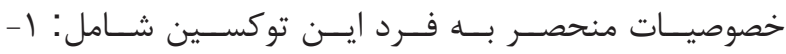

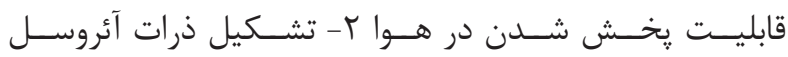

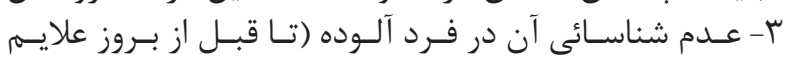

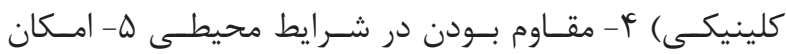

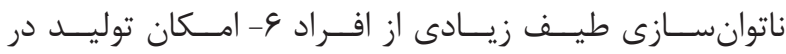

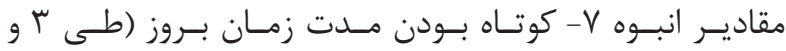

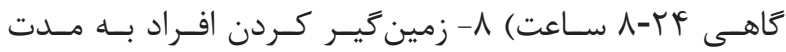

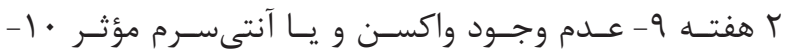

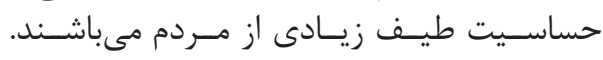

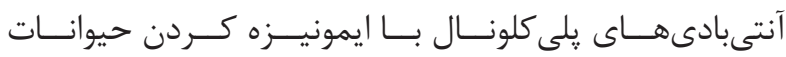

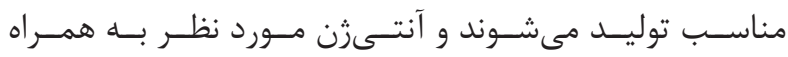

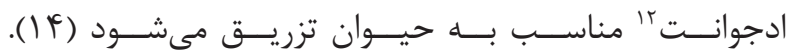

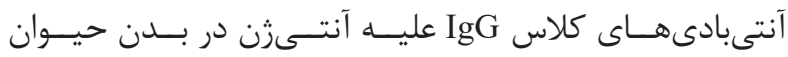

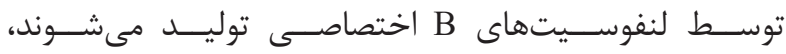

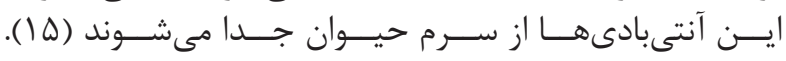

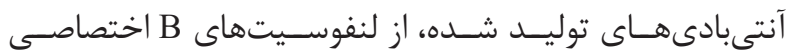

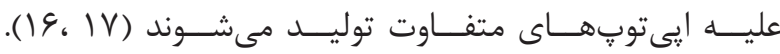

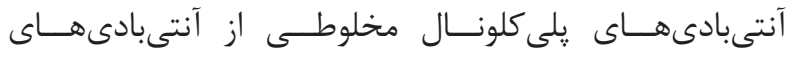

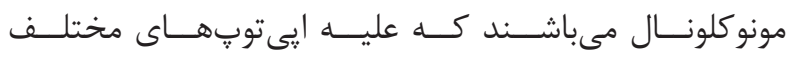

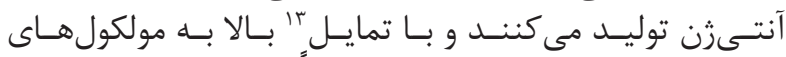

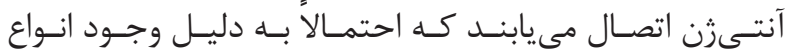

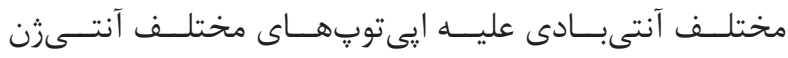

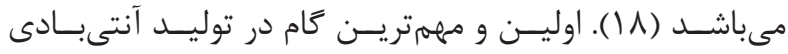

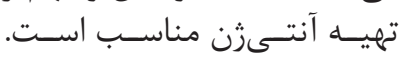

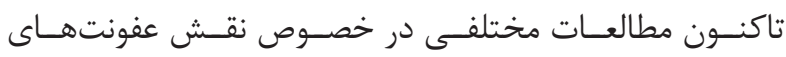

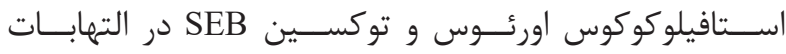

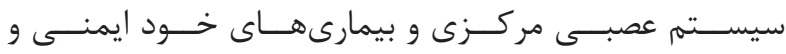

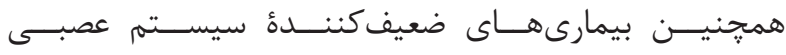

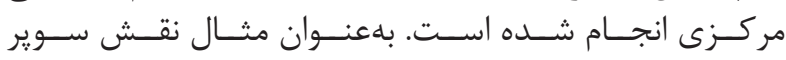

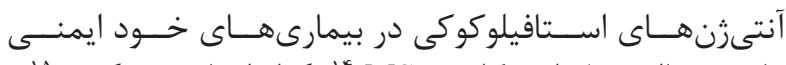

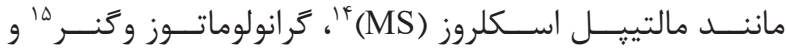

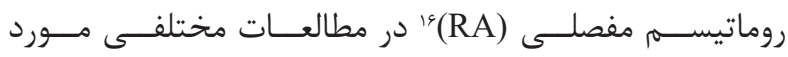

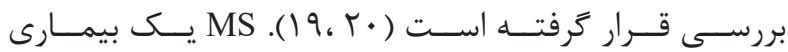

\footnotetext{
${ }^{1}$ Staphylococcal enterotoxins

${ }^{2}$ Superantigen

${ }^{3}$ Toxic shock syndrome toxin- 1

${ }^{4}$ Toxic

${ }^{5}$ Staphylococcus B enterotoxin

${ }^{6}$ Centers for disease control

${ }^{7}$ Proteolytic

${ }^{8}$ Antigen presenting cell
}

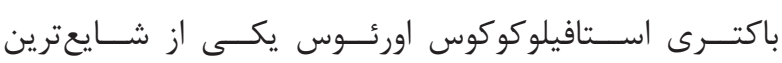

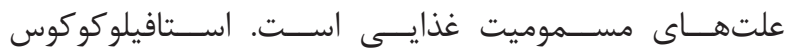

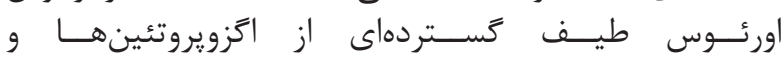

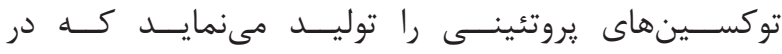

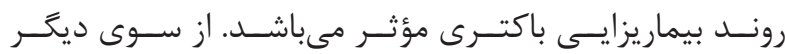

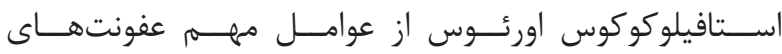

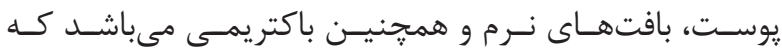

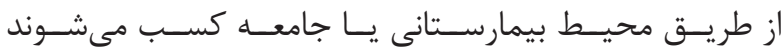

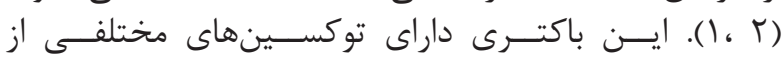

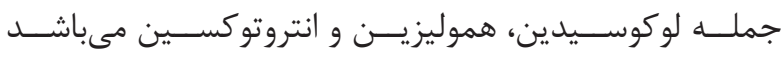

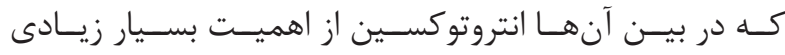

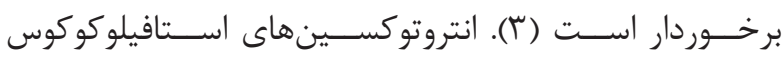

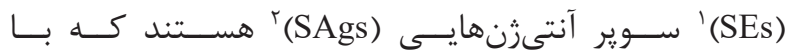

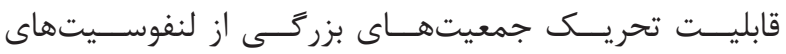

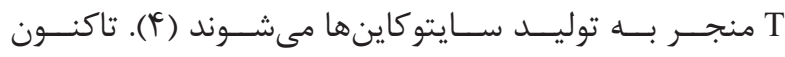

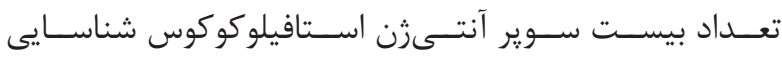

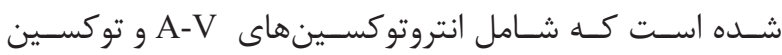

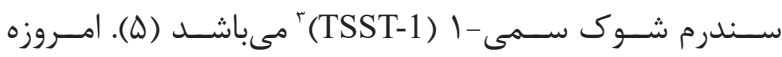

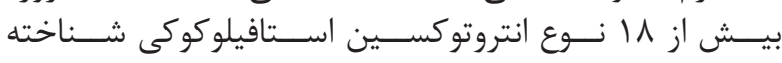

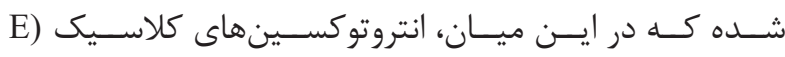

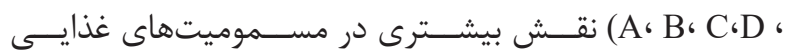

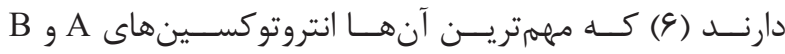

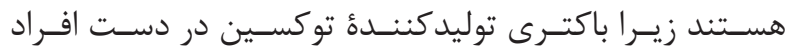

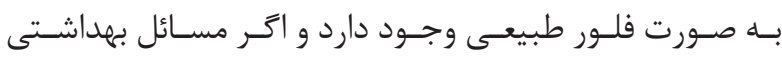

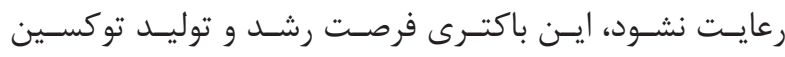

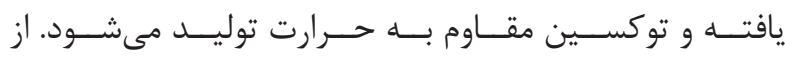

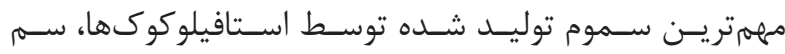

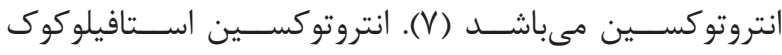

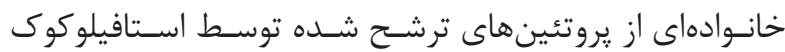

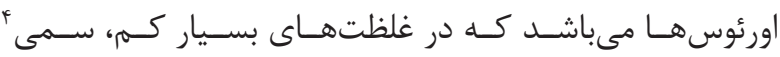

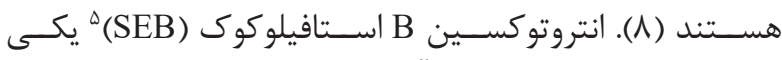

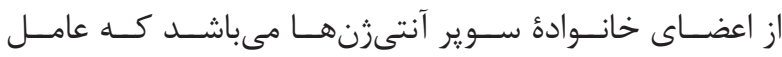

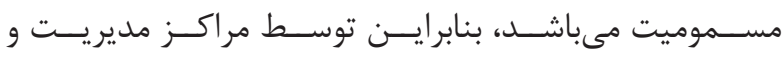

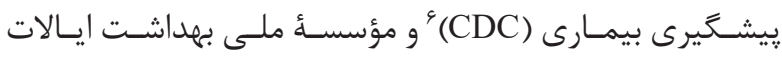

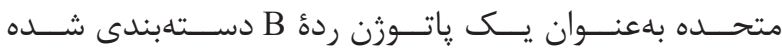

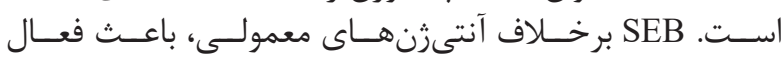

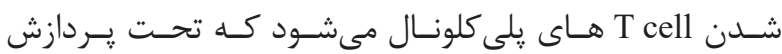

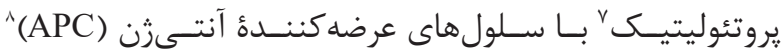

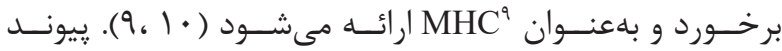

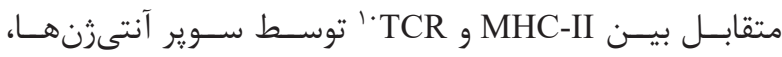

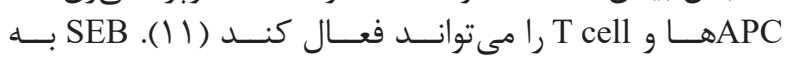

\footnotetext{
${ }^{9}$ Major histocompatibility complex

${ }^{10} \mathrm{~T}$-cell receptor

${ }^{11}$ Effective dose

${ }^{12}$ Adjuvant

${ }^{13}$ Affinity

${ }^{14}$ Multiple sclerosis

${ }^{15}$ Wegener's granulomatosis

${ }^{16}$ Rheumatoid arthritis
} 


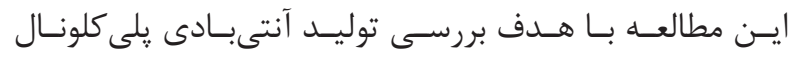

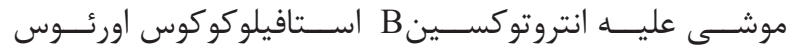

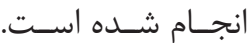

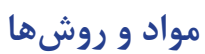

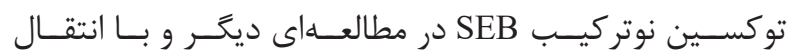

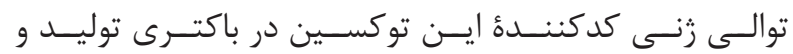

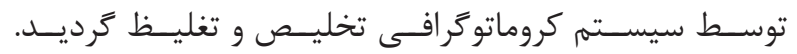

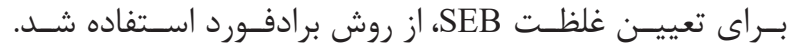

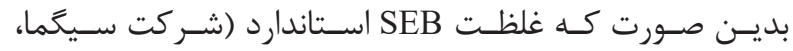

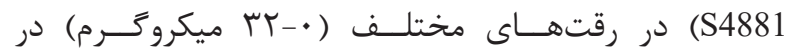

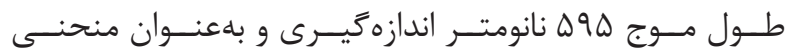

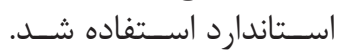

\section{SDS-PAGE}

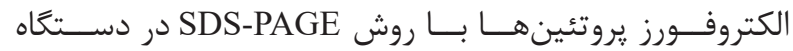

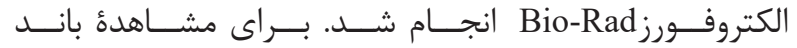

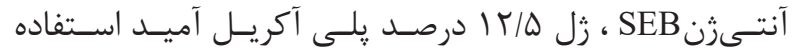

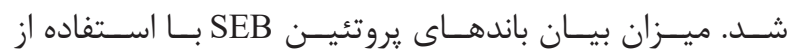

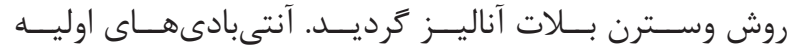

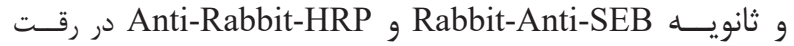

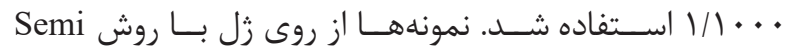

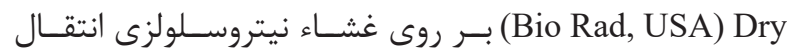

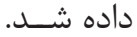

$$
\text { توليد توكسوئيد انتروتوكسين }
$$

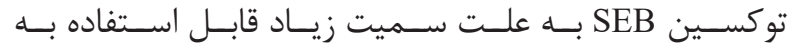

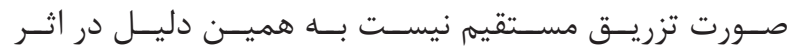

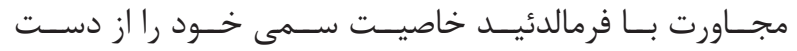

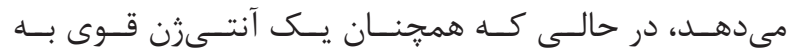

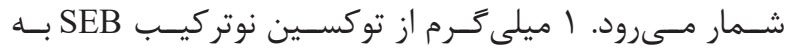

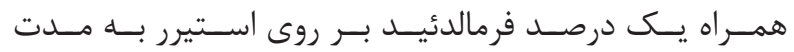

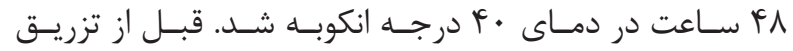

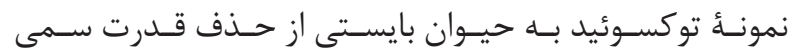

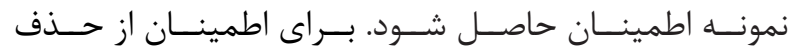

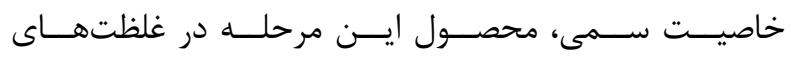

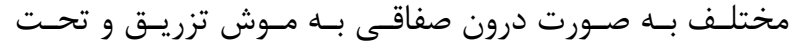

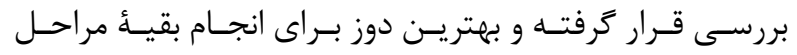

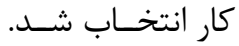

$$
\text { تهيئة آنتىبادى }
$$

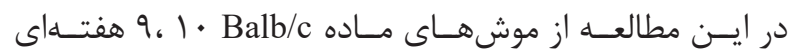

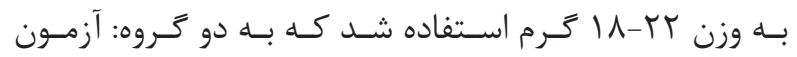

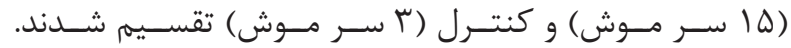

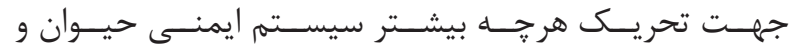

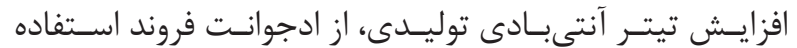

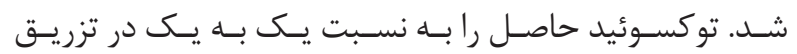

${ }^{17}$ Central nervous system

${ }^{18}$ Neurodegeneration

${ }^{19}$ Experimental autoimmune encephalomyelitis

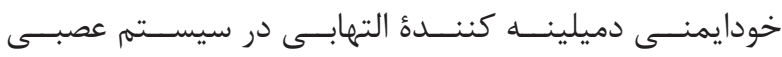

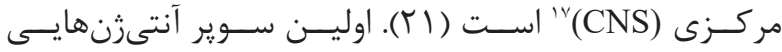

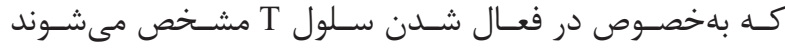

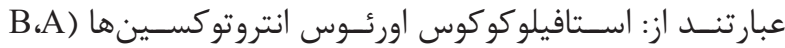

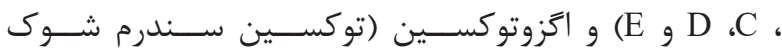

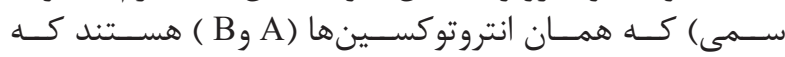

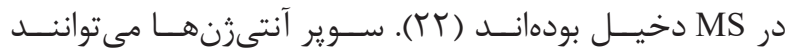

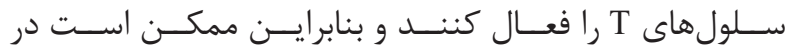

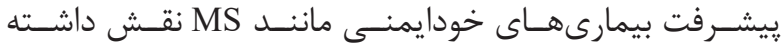

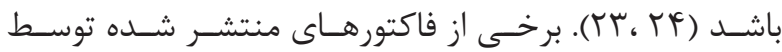

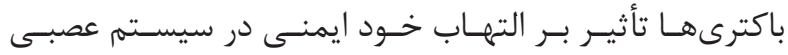

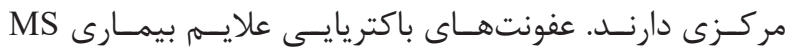

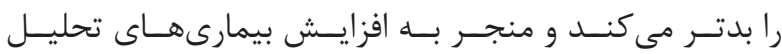

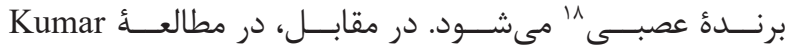

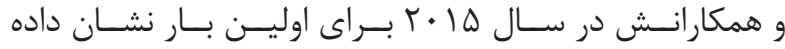

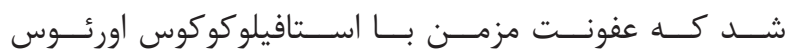

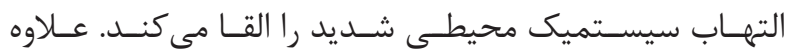

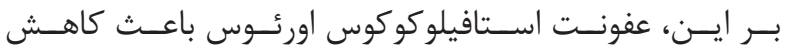

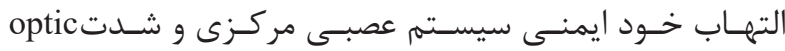

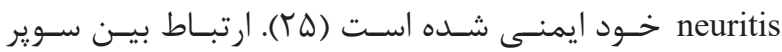

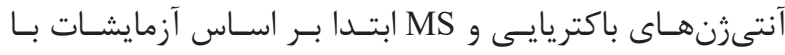

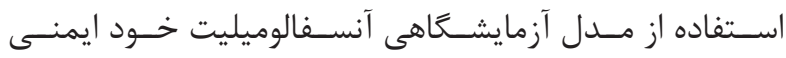

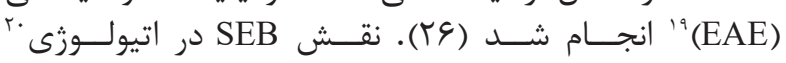

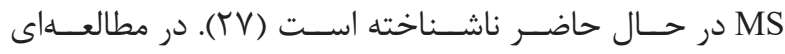

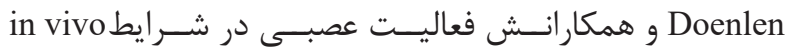

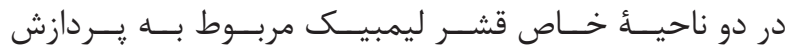

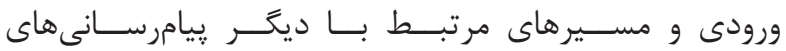

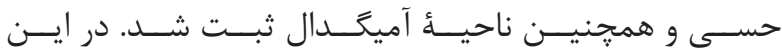

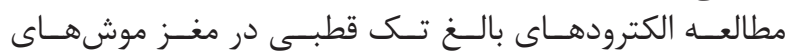

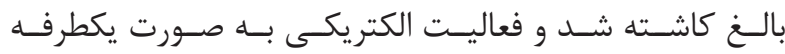

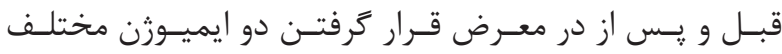

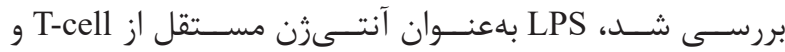

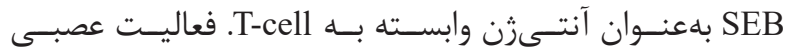

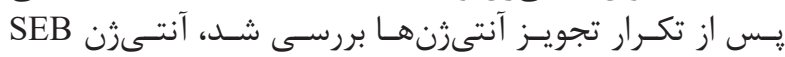

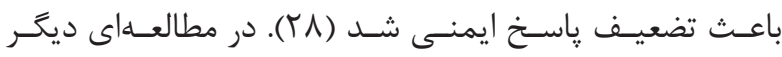

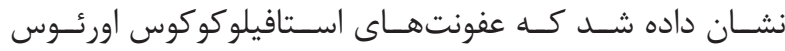

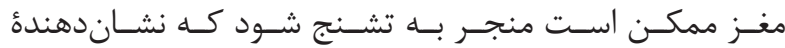

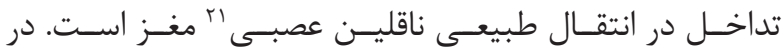

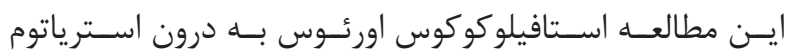

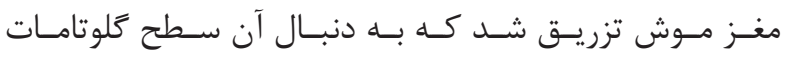

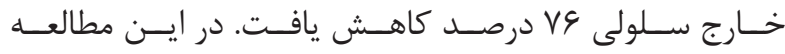

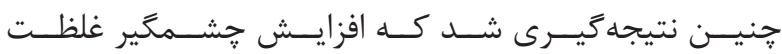

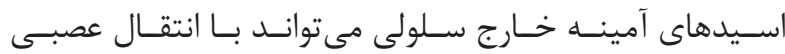

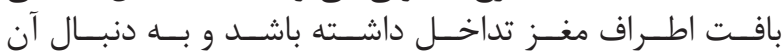

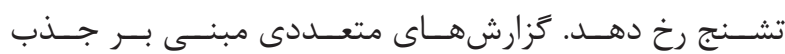

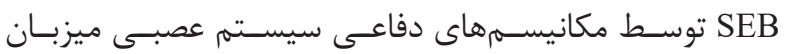
وجــود دارد (rq) تون مكان.

${ }^{20}$ Etiology

${ }^{21}$ Neurotransmitters 


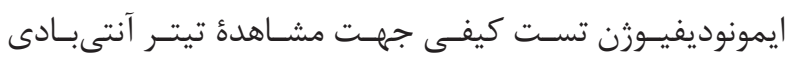

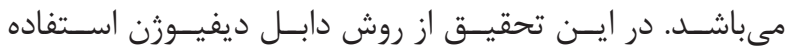

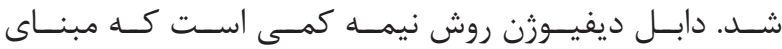

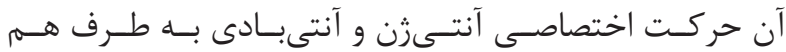

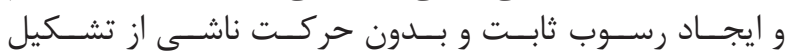

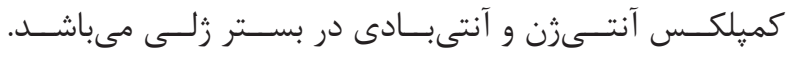

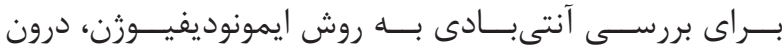

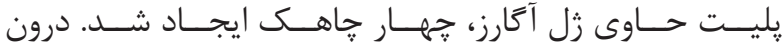

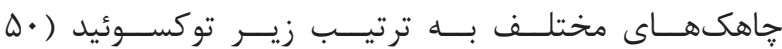

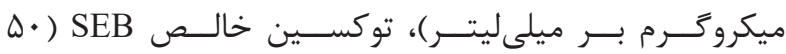

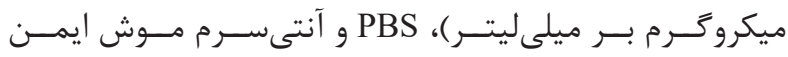

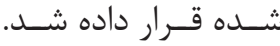

نافته ها

غلظت هروتئين

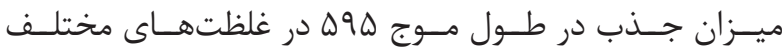

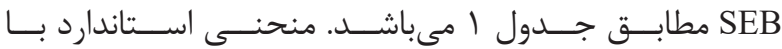

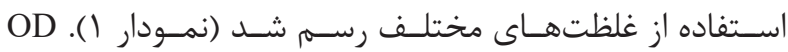

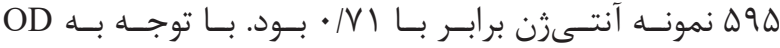

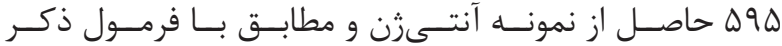

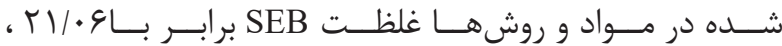
تعييـن خرديـد.

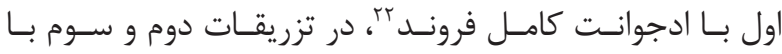

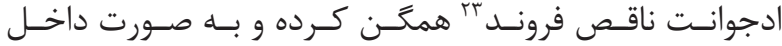

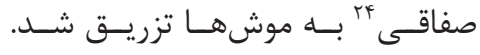
الايزا

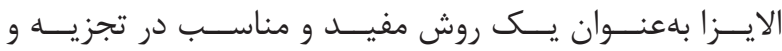

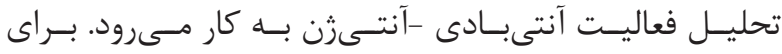

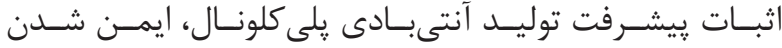

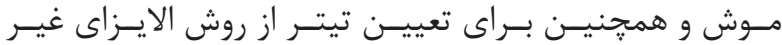

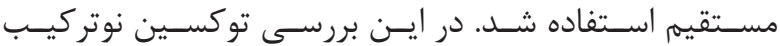

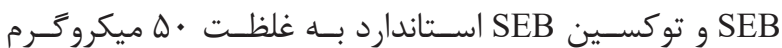

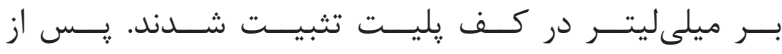

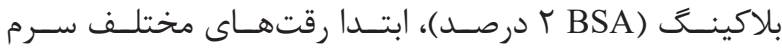

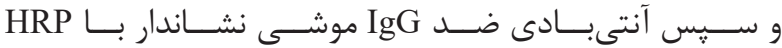

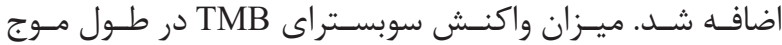

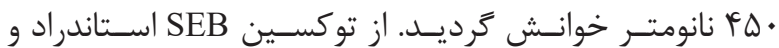

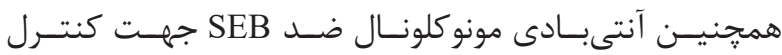

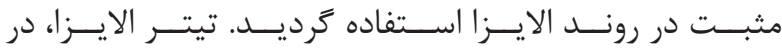

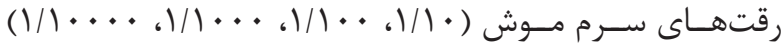

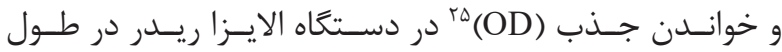

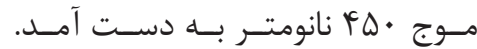

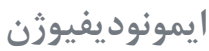

جدول ا-مقادير يروتئين SEB و مقدار جذب آنها در ه9ه نانومتر.

\begin{tabular}{|c|c|c|c|c|c|c|c|c|c|c|c|}
\hline ميكروثرم & ميكروكرم & ميكروكرم & ميكروكرم & ميكروثرم & ميكروكرم & ميكروكرم & ميكروكرم & ميكروكرم 19 & ميكروكرم & ميكروكرم & غر غلظت يروتثنين \\
\hline .1. & .1 .99 & $.1 . \varphi^{\mu}$ &.$/ 11 r$ & . & $\cdot / T \Lambda G$ & . & $\cdot \mid K \Lambda$ & . &.$/ 189$ &.$/ 9 \mathrm{VT}$ & OD \\
\hline
\end{tabular}

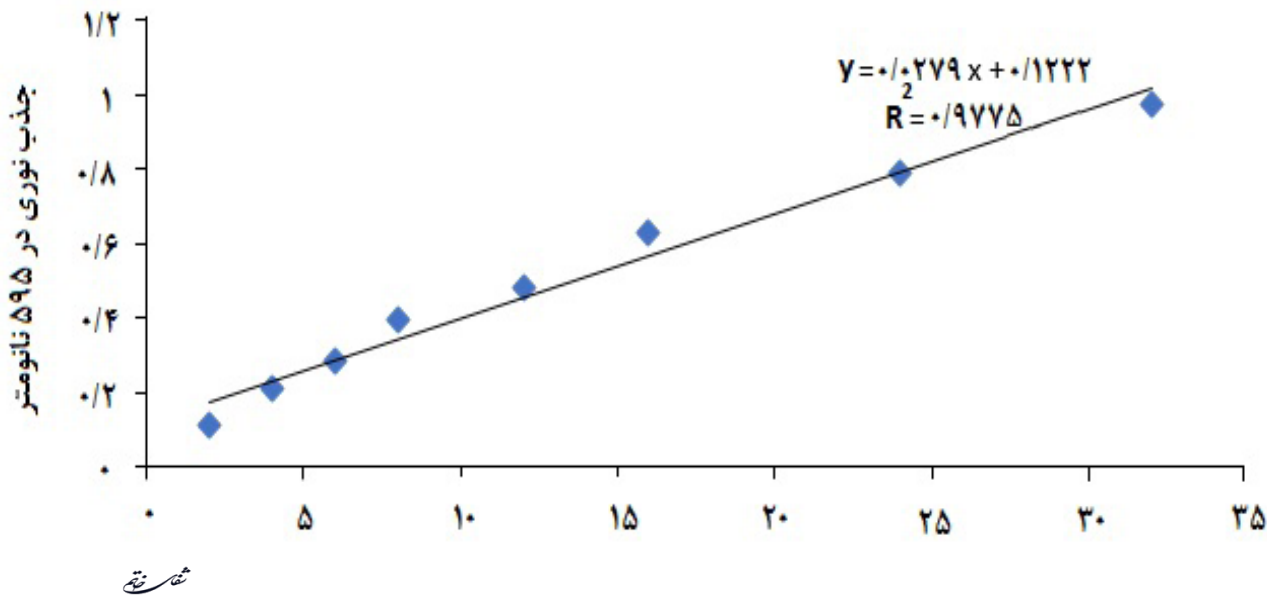

غلظت يروتئين

نمودار ا- منحنى استاندارد معرف برادفورد جهت اندازميرى غلظت يروتئين.

${ }^{22}$ Freunds complete adjuvant

${ }^{23}$ Freunds incomplete adjuvant

\footnotetext{
${ }^{24}$ Intraperitoneal

${ }^{25}$ Optical density
} 


$$
\text { تاييد ايمنسازى با الايزا }
$$

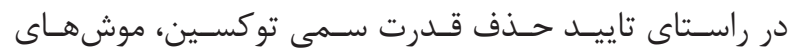

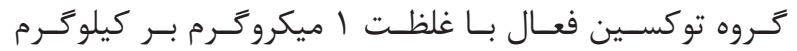

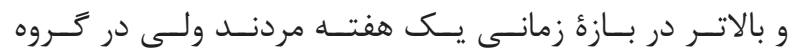

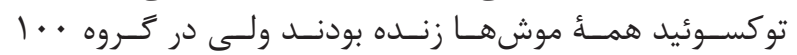

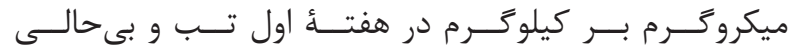

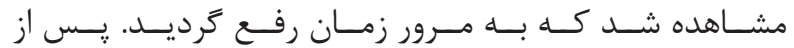

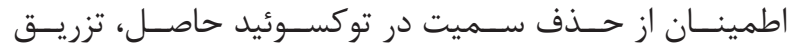

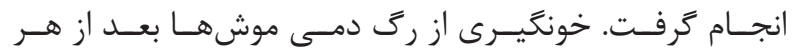

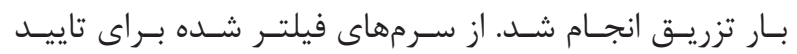

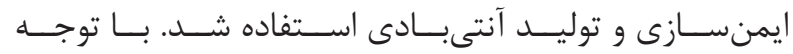

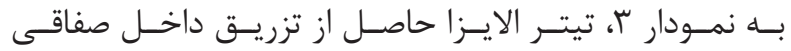

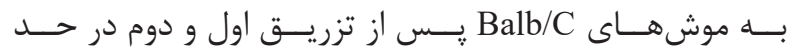

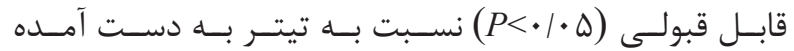

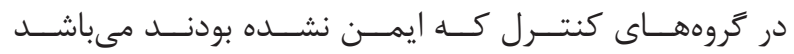

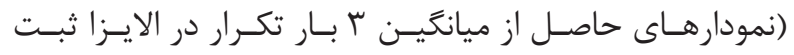

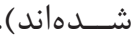

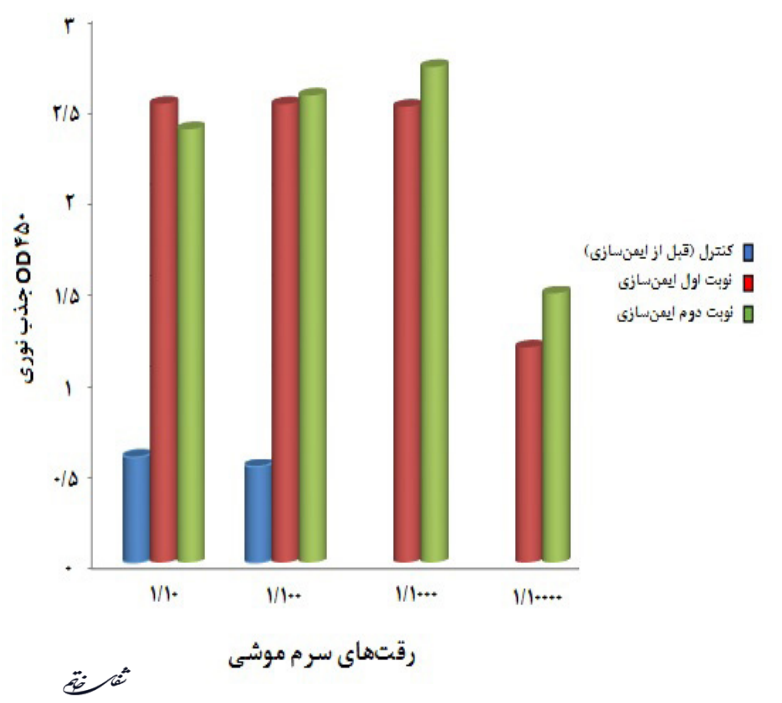

نمودار ب- تيتر الايزاى نمونهاى سرم خون موش. زل ديفيورن توكسين و توكسوئ

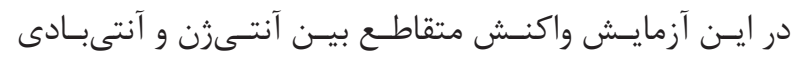

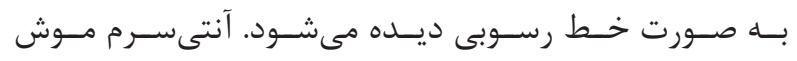

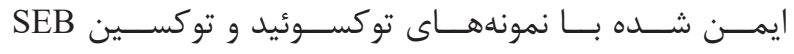

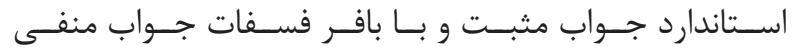
نشـان داد. بحث و نتيجه كَيرى

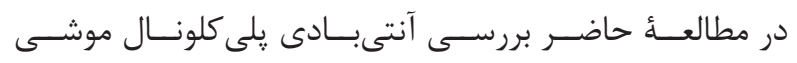

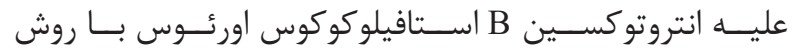

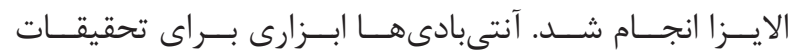

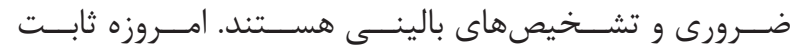

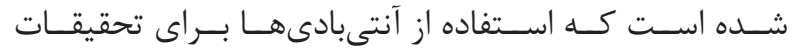

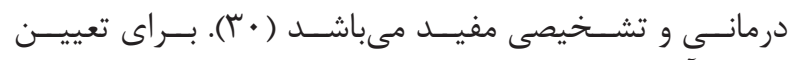

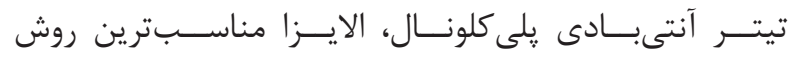

SEB و وسترن بلات آنتى SDS-PAGE

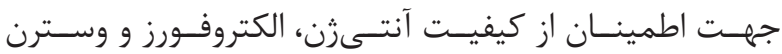

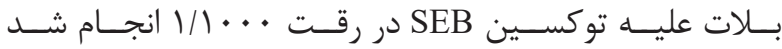

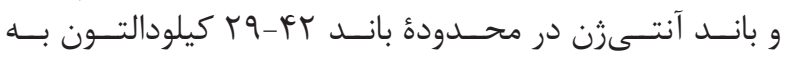

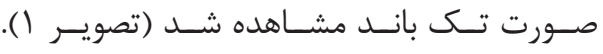

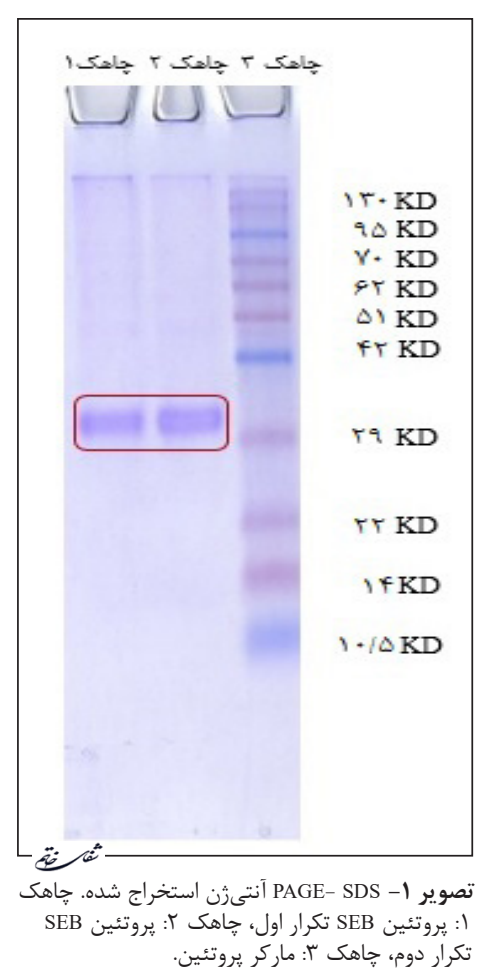

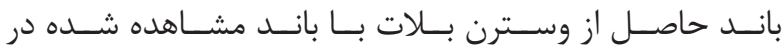

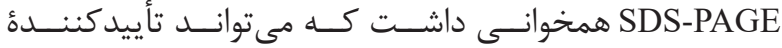

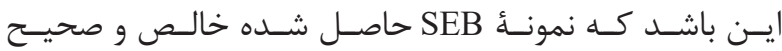

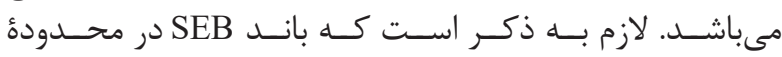

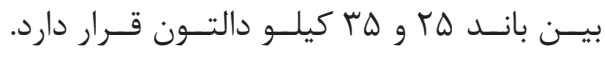

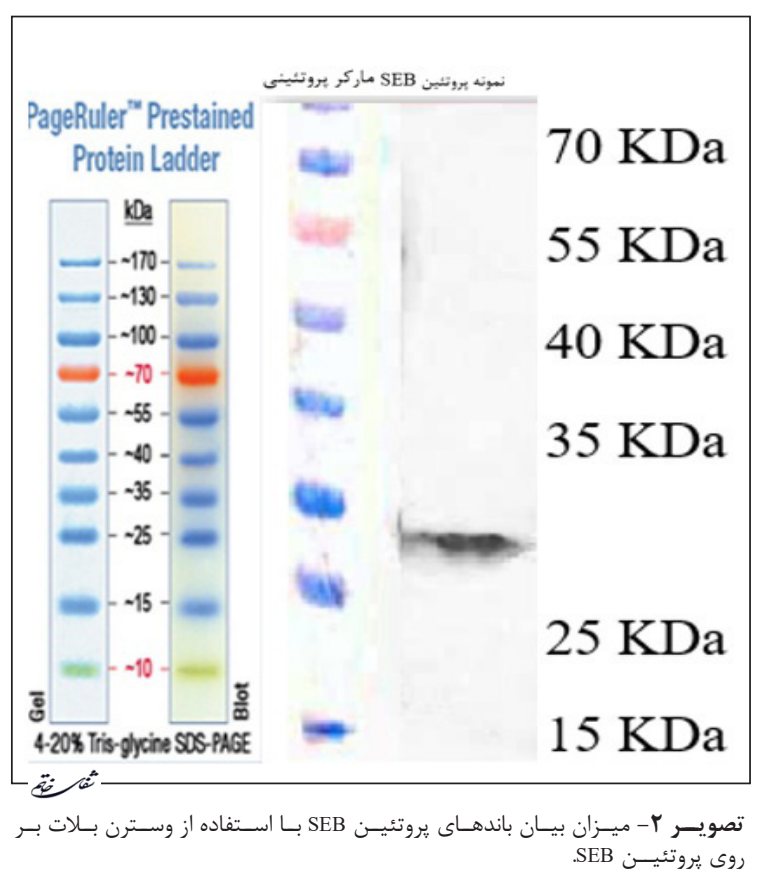




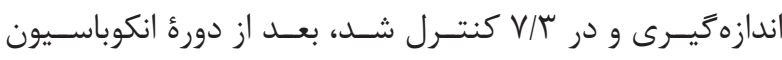

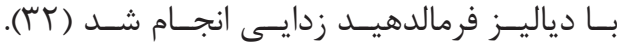

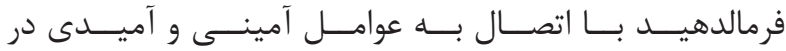

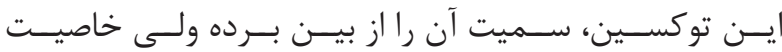

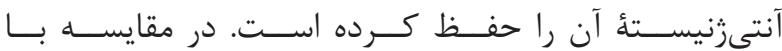

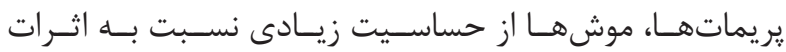

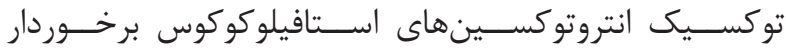

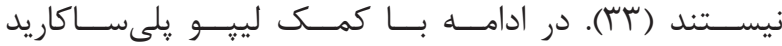

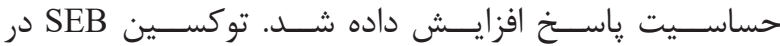

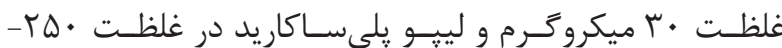

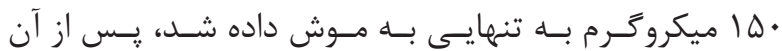

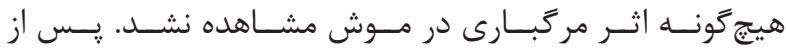

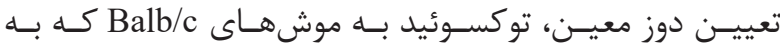

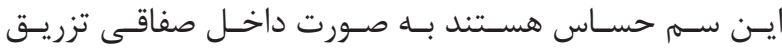

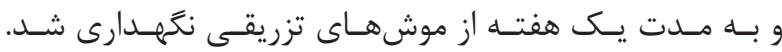

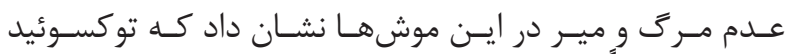

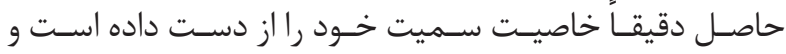

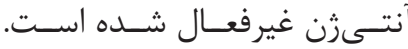

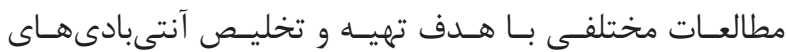

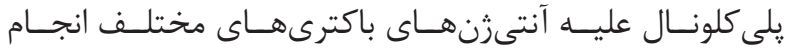

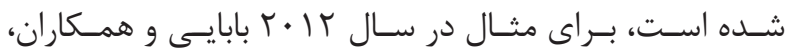

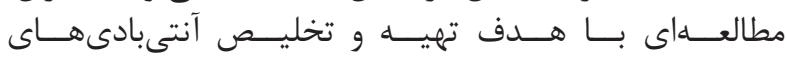

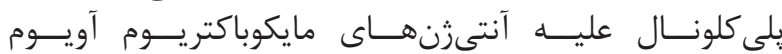

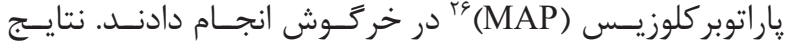

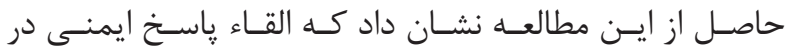

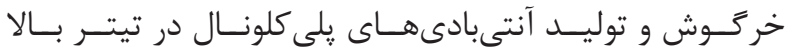

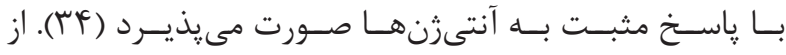

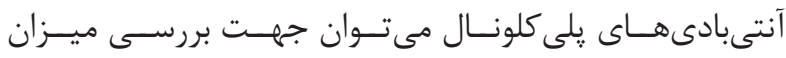

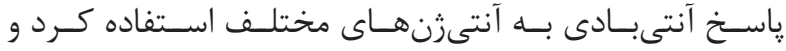

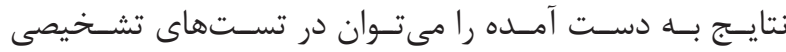

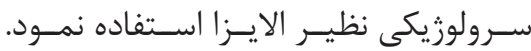

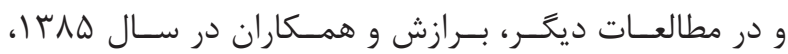

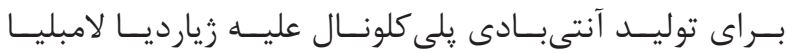

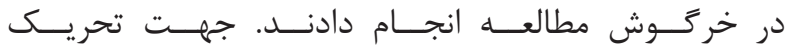

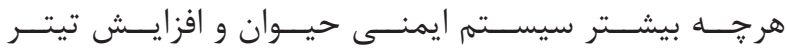

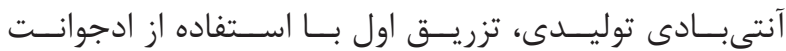

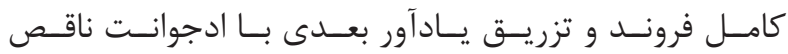

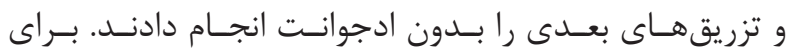

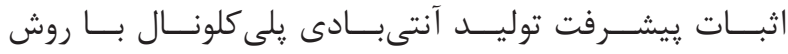

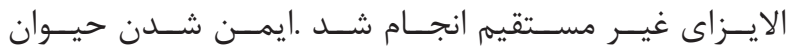

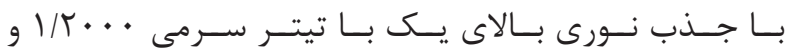

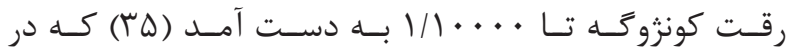

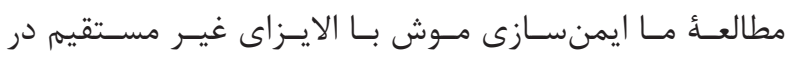

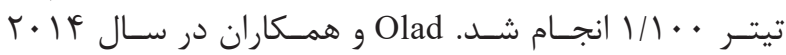

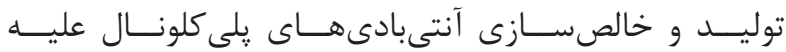

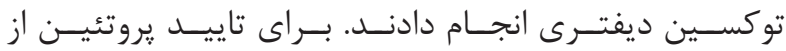

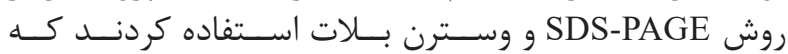

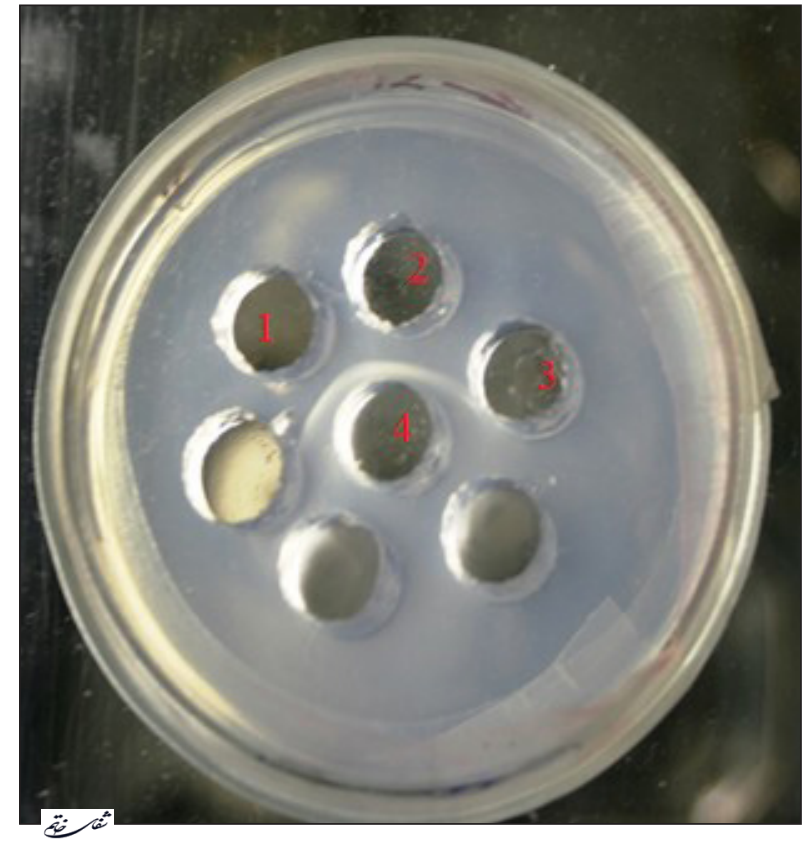

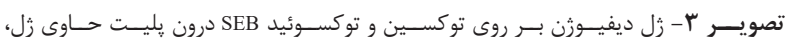

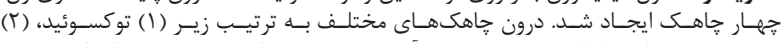

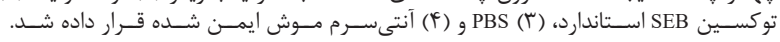

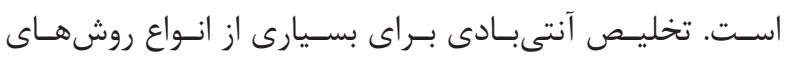

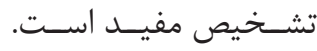

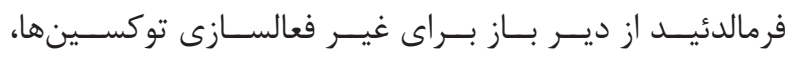

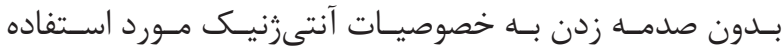

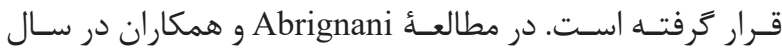

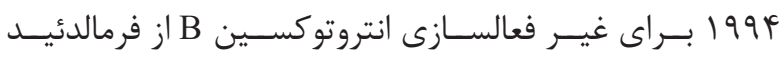

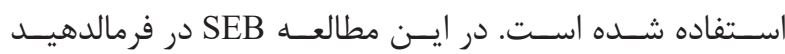

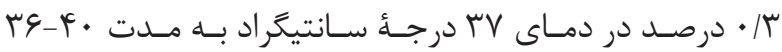

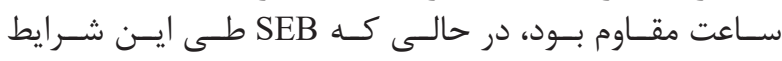

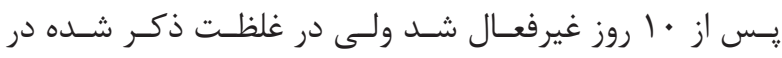

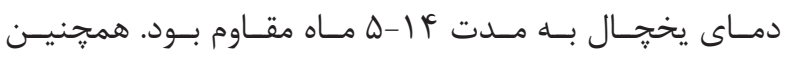

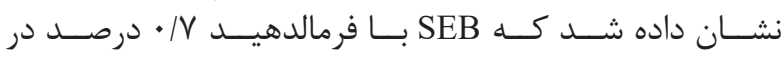

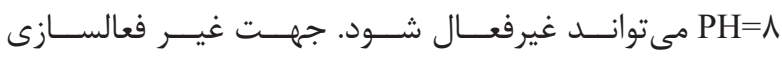

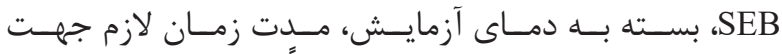

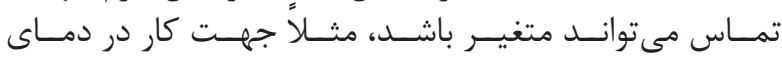

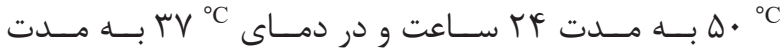

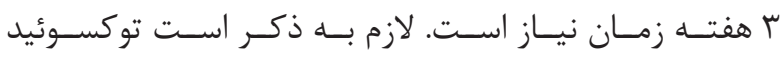

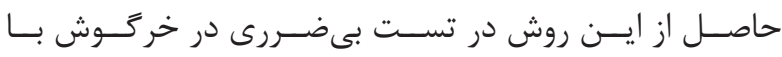

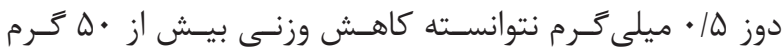

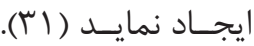

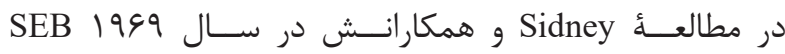

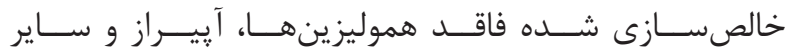

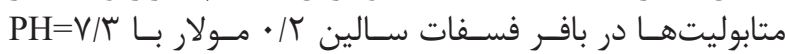

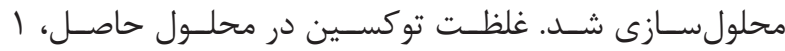

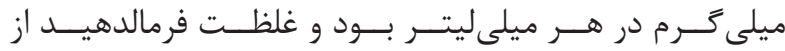

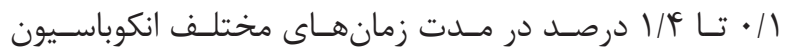

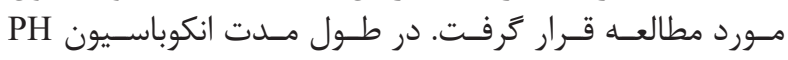




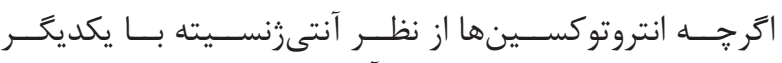

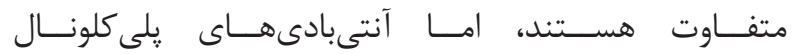

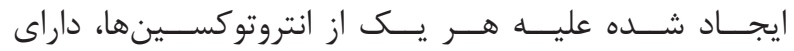

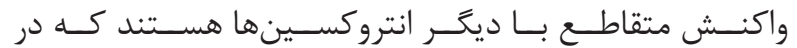

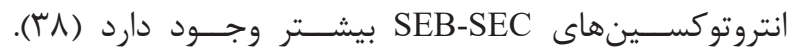

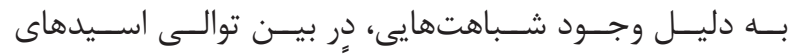

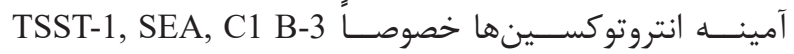

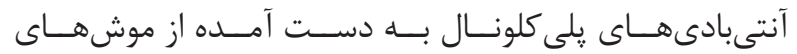

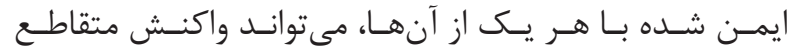

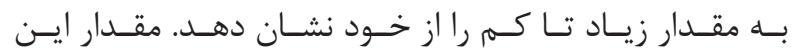

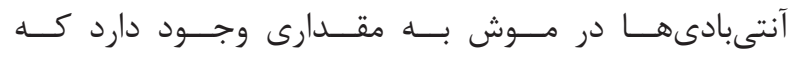

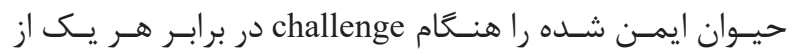

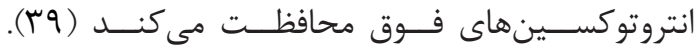

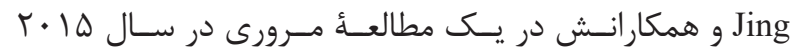

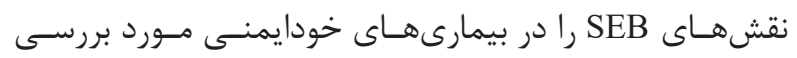

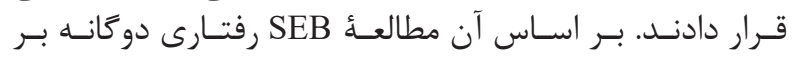

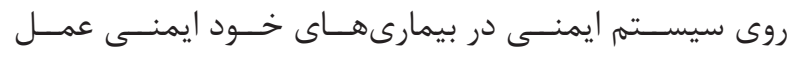

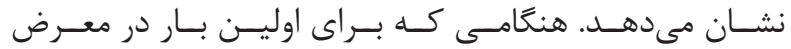

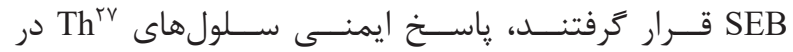

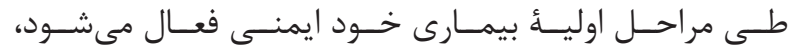

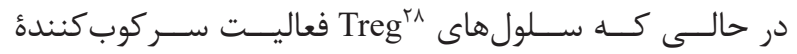

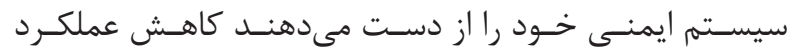

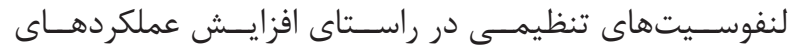

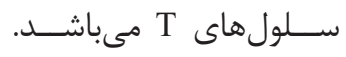

Mousavi

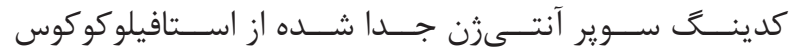

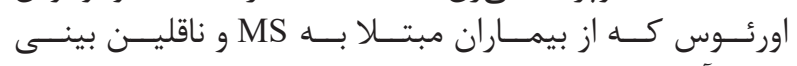

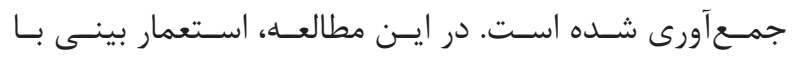

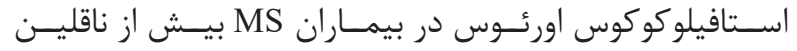

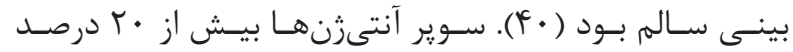

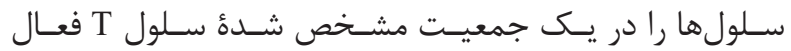

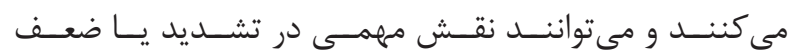

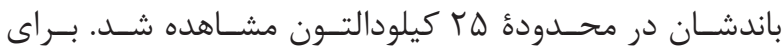

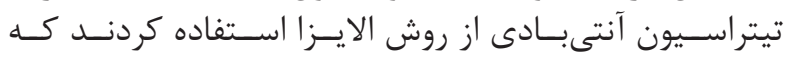

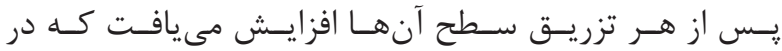

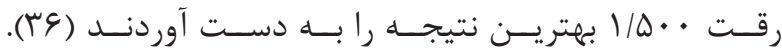

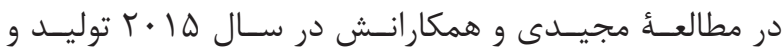

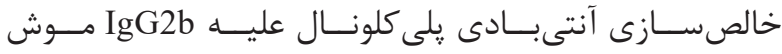

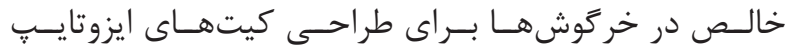

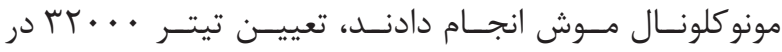

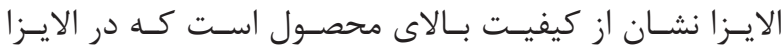

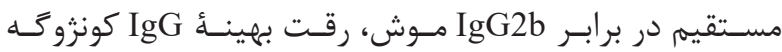

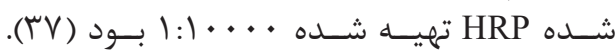

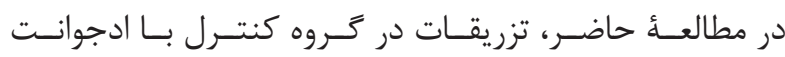

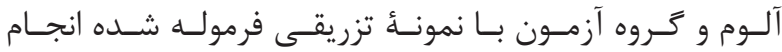

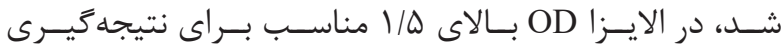

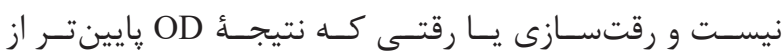

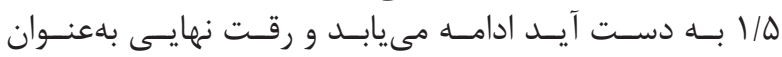

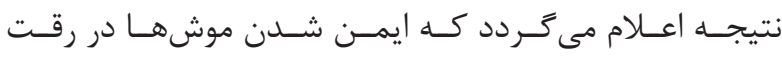

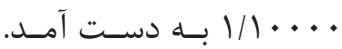
جدول r- معرفى انتروتوكسينها.

\begin{tabular}{|c|c|}
\hline 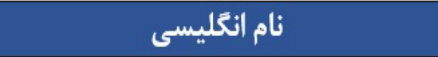 & 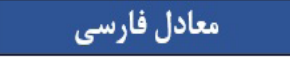 \\
\hline Staphylococcal enterotoxin A; (SEA) & انتروتوكسين استافيلوكوكى A \\
\hline Staphylococcal enterotoxin B; (SEB) & انتروتوكسين استافيلوكوكى B \\
\hline Staphylococcal enteroto & انتروتوكسين استافيلوكوكى C1 \\
\hline Staphylococcal enterotoxin D; (SED) & انتروتوكسين استافيلوكوكى D \\
\hline $\mathrm{E} ;(\mathrm{SEE})$ & انتروتوكسين استافيلوكوكى E \\
\hline Staphylococcal enterotoxin G; (SEG) & انتروتوكسين استافيلوكوكى G \\
\hline Staphylococcal enterotoxin I; (SEI) & انتروتوكسين استافيلوكوكى I I \\
\hline Staphylococcal enterotoxin J; (SEJ) & انتروتوكسين استافيلوكوكى J \\
\hline Staphylococcal enterotoxin M; (SEM) & انتروتوكسين استافيلوكوكى M \\
\hline Staphylococcal enterotoxin N; (SEN) & انتروتوكسين استافيلوكوكى N \\
\hline Staphylococcal enterotoxin O; (SEO) & انتروتوكسين استافيلوكوكى O \\
\hline
\end{tabular}

جدول بـ - ميزان شباهت توالى اسيدهاى آمينه در بين انتروتوكسينها.

\begin{tabular}{|c|c|c|c|c|c|c|c|c|c|c|c|c|}
\hline توكسين & SEA & SEB & $\mathrm{EC} 1$ & SED & SEE & EEG & SEH & SEI & SEJ & SEM & SEN & SEO \\
\hline SEA & $1 \ldots$ & rr & $r$. & $\Delta$. & $\Lambda \mathrm{r}$ & TV & rV & rq & 94 & ro & rq & $r v$ \\
\hline SEB & & $1 \ldots$ & 91 & ra & rr & Fr & זr & $r_{1}$ & rr & rq & rr & קq \\
\hline SEC1 & & & $1 \ldots$ & ז & rq & \&1 & TV & re & $r$. & rG & rq & זr \\
\hline SED & & & & $1 \ldots$ & $\Delta r$ & rV & ra & r & $\Delta 1$ & fi & ru & rq \\
\hline SEE & & & & & $1 \ldots$ & rV & ra & $r \Delta$ & $q \mu$ & rV & rq & rV \\
\hline SEG & & & & & & $1 \ldots$ & rf & $r \Lambda$ & $r q$ & $r \Lambda$ & r & $r$. \\
\hline SEH & & & & & & & $1 \ldots$ & rr & $r \Delta$ & r & HF & ז \\
\hline SEI & & & & & & & & $1 \ldots$ & rf & r & ו & $\Delta V$ \\
\hline SEJ & & & & & & & & & $1 \ldots$ & r & fr & זس \\
\hline SEM & & & & & & & & & & $1 \ldots$ & rA & r \\
\hline SEN & & & & & & & & & & & $1 \ldots$ & fr \\
\hline SEO & & & & & & & & & & & & $1 \ldots$ \\
\hline
\end{tabular}

${ }^{27} \mathrm{~T}$ helper cell

${ }^{28}$ Regulatory T cells 


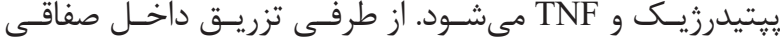

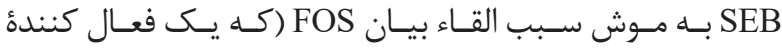

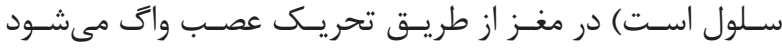

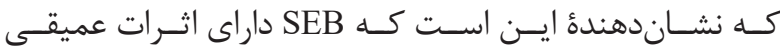

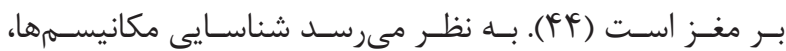

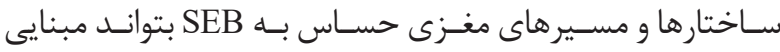

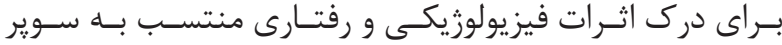

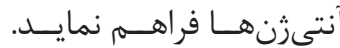

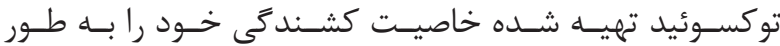

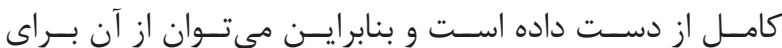

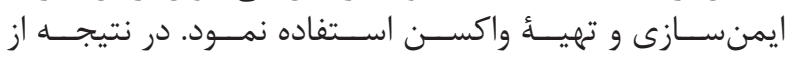

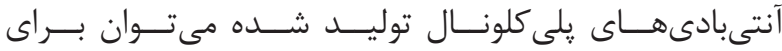

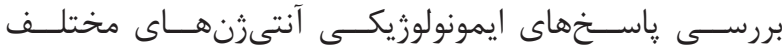

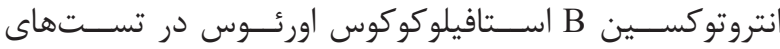
مختلـف اسـتفاده كـرد.

1. Balaban N, Rasooly A. Staphylococcal enterotoxins. Int J Food Microbiol. 2000; 61: 1-10.

2. Tomi NS, Kranke B, Aberer E. Staphylococcal toxins in patients with psoriasis, atopic dermatitis, and erythroderma, and in healthy control subjects. J Am Acad Dermatol. 2005; 53: 67-72.

3. Atanassova V, Meindl A, Ring C. Prevalence of staphylococcus aureus and staphylococcal enterotoxins in raw pork and uncooked smoked ham-a comparison of classical culturing detection and rflp-pcr. Food Microbiol. 2001; 68: 1-2.

4. Abbasi S, Taei S, Zamanzad B. The prevalence of methicillin-resistant staph. Aureus Strains Producing Enterotoxin A and B. Tehran University Medical. 2015; 11: 73 .

5. Al-Daccak R, Mehindate K, Damdoumi F, EtonguéMayer P. Staphylococcal enterotoxin D is a promiscuous superantigen offering multiple modes of interactions with the mhe class ii receptors. J Immunol. 1998; 160(1): 225-32.

6. Akineden O, Hassan Aa, Schneider E, Usleber E. Enterotoxigenic properties of staphylococcus aureus isolated from goats' milk cheese. Food Microbiol. 2008; 124(2): 211-6.

7. Balaban N. Rasooly A. Staphylococcal Enterotoxins Int J Food Microbiol. 2000; 61(1): 1-10.

8. Verreault D, Ennis J, Whaley K, Z Killeen S, Karauzum $\mathrm{H}$, Aman MJ, et al. Effective treatment of staphylococcal enterotoxin $\mathrm{B}(\mathrm{Seb})$ aerosol intoxication in rhesus

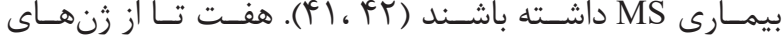

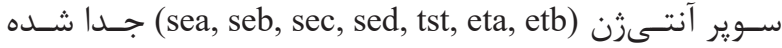

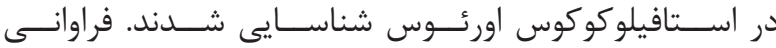

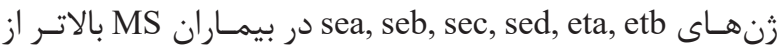
حاملهــاى سـالم بينسى بودنــد.

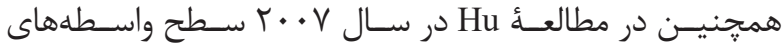

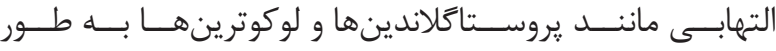

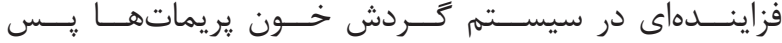

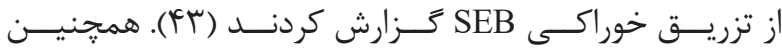
Mast cell

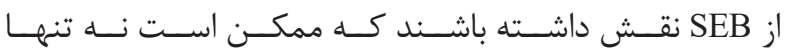

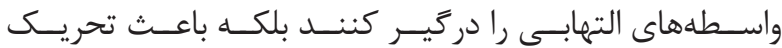

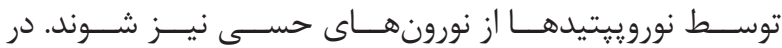

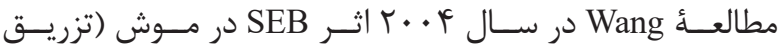

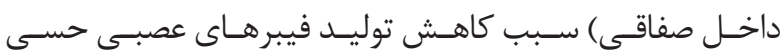

منابع macaques using two parentally-administered high affinity monoclonal antibodies. Antimicrob Agents Chemother. 2019; 63(5): e02049-18. doi: 10.1128/AAC.02049-18.

9. Stiles BG, Bavari S, Krakauer T, Ulrich RG. Toxicity of staphylococcal enterotoxins potentiated by lipopolysaccharide: major histocompatibility complex class ii molecule dependency and cytokine release. Infect Immun. 1993; 61(12): 5333-8.

10. Drake CG, Kotzin BL. Superantigens: biology, immunology, and potential role in disease. Journal of Clinical Immunology. 1992; 12(3): 149-62.

11. Stephen JD, Bellsteven M, Vroegopstephen EB. Early activation and cell trafficking induced by staphylococcal enterotoxin b: effects of high- versus low-dose challenge on induction of anergy. Cellular Immunology. 1994; 154(2): 440-52.

12. Saeed AI, RIEDER SA, Price Rl, Barker J, Nagarkatti P, Nagarkatti M. acute lung injury induced by staphylococcal enterotoxin $\mathrm{b}$ : disruption of terminal vessels as a mechanism of induction of vascular leak. Microscopy and Microanalysis. 2012; 18(3): 445-52.

13. Kitano K, Fukuda Y, Nagahira K, Nasu T, Noguchi C, Izumi R, et al. Production of polyclonal antibody specific for human natriuretic peptide receptor B. J Immunol Methods. 1996; 194(2): 147-53.

14. Maneian M, Zarkesh Esfahani SH, Akbari M, Khanahmad H, Masjedi M. Production of polyclonal antibody against recombinant growth hormone and designing an elisa kit and comparing some of its diagnostics indices with a commercial kit. Journal of 
Isfahan Medical School. 2013; 31(247): 1173-84.

15. Majidi J, Abdolalizadeh J, Amirkhiz MB, Majidi S. Production and purification of polyclonal antibody against bovine immunoglobulins in rabbits. African Journal of Biotechnology. 2007; 6(12).

16. Diestre C, Martinez-Lorenzo Mj, Bosque A, Naval J, Larrad L, Anel A. Generation of rabbit antibodies against death ligands by cdna immunization. Journal of Immunological Methods. 2006; 317(1-2): 12-20.

17. Stiles BG, Garza AR, Ulrich RG, Boles JW. Mucosal Vaccination with Recombinantly Attenuated Staphylococcal Enterotoxin B and Protection in a Murine Model. Infection and Immunity. 2001; 69(4): doi: $\quad$ 10.1128/IAI.69.4.2031-2036.2001.

18. Mulvey MR, Doupe M, Prout M, Leong C, Hizon R, Grossberndt A, et al. Staphylococcus aureus harbouring Enterotoxin A as a possible risk factor for multiple sclerosis exacerbations. Mult. Scler J. 2011; 17(4): 397-403.

19. Jing Li, Jie Yang, Yu-wei Lu, Song Wu, Ming-rui Wang, Ji-min Zhu. Possible role of staphylococcal enterotoxin $\mathrm{B}$ in the pathogenesis of autoimmune diseases. Viral Immunology. 2015; 28(7): doi. org/10.1089/vim.2015.0017.

20. Libbey JE, Cusick MF, Fujinami RS. Role of pathogens in multiple sclerosis. International Reviews of Immunology. 2013; 33(4): 1-18.

21. Torres BA, Kominsky S, Perrin GQ. Superantigens: the good, the bad, and the ugly. Exp Biol Med. 2001; 226: $164-76$.

22. Schiffenbauer J, Johnson HM, Butfiloski EJ. Staphylococcal enterotoxins can reactivate experimental allergic encephalomyelitis. Proc Natl Acad Sci USA. 1993; 90: 8543-6.

23. Brocke S, Gaur A, Piercy C, Gautam A, Gijbels $\mathrm{K}$, Fathman $\mathrm{G}$, et al. Induction of relapsing paralysis in experimental autoimmune encephalomyelitis by bacterial superantigen. Nature. 1993; 365: 642-4.

24. Kumar P, Kretzschmar B, Herold S, Nau R, Kreutzfeldt M, Schütze S, et al. Beneficial effect of chronic Staphylococcus aureus infection in a model of multiple sclerosis is mediated through the secretion of extracellular adherence protein. Journal of Neuroinflammation. 2015; 12-22.

25. Mulvey MR, Doupe M, Prout M, Leong C, Hizon R, Grossberndt A, et al. Staphylococcus aureus arbouring
Enterotoxin A as a possible risk factor for multiple sclerosis exacerbations. Mult. Scler. 2011; 4: 397-403.

26. Singh BR, Evenson ML, Bergdoll MS. Structural analysis of staphylococcal enterotoxins B and C1 using circular dichroism and fluorescence spectroscopy. Biochemistry 1988; 27(24): 8735-41.

27. Doenlen R, Krügel U, Wirth T, Riether C, Engler A, Prager $\mathrm{G}$, et al. Electrical activity in rat cortico-limbic structures after single or repeated administration of lipopolysaccharide or staphylococcal enterotoxin B. Proc Biol Sci. 2011; 278(1713): 1864-72.

28. Serrats J, Sawchenko PE. CNS activational responses to staphylococcal enterotoxin B: T-lymphocytedependent immune challenge effects on stress-related circuitry. J Comp Neurol. 2006; 495(2): 236-54.

29. Oshvandi K, Jokar M, Khatiban M, Keyani J, Yousefzadeh MR, Sultanian AR. the effect of self-care education based on teach back method on promotion of self care behaviors in type ii diabetic patients: a clinical trial study. Diabetes and Metabolism. 2014; 13(2).

30. Tommaso A di, de Magistris MT, Bugnoli M, Marsili I, Rappuoli R, Abrignani S. formaldehyde treatment of proteins can constrain presentation to $t$ cells by limiting antigen processing. Infect Immun. 1994; 62(5): 1830-4.

31. Coffman D, Zhu J, Roach J, Bavari S, Ulrich R, Giardina S. Production and Purification of A Recombinant Staphylococcal Enterotoxin B Vaccine Candidate Expressed in Escherichia Coli. Protein Expr Purif. 2002; 24(2): 302-12.

32. Hu DL., Zhu G., Mori F., Omoe K., Okada M., Wakabayashi K, et al. Staphylococcal enterotoxin induces emesis through increasing serotonin release in intestine and it is downregulated by cannabinoid receptor 1. Cell Microbiol. 2007; 9: 2267-77.

33. Silverman SJ, Espeseth DA, Schantz EJ. Effect of Formaldehyde on The Immunochemical and Biological Activity of Staphylococcal Endotoxin B. J Bacteriol. 1969; 98(2): 437-42.

34. Alizadeh H, Madani R, Babaie M, Kavid N, Golchinfar F, Emami T. Preparation and purification of polyclonal antibodies against mycobacterium avium paratuberculosis antigens in rabbit. J Fasa Univ Med Sci. 2012; 2(3): 168-73.

35. Barazesh A, Majidi J, Fallah E, Jamali R, Khazanchi A, Abdolalizadeh J. Prodution of polyclonal antibody against giardia lamblia in rabbit. Ilam University of Medical Sciences. 2007; 14(4). 
36. Arefpour Torabi MA, Olad GR, Nazarian G, Salimian J, Khodi S, Bagheripour MJ. Production and purification of polyclonal antibodies against diphtheria toxin. Applied Biotechnology Reports. 2014; 2(1): 67-72.

37. Eivazi S, Majidi J, Aghebati Maleki L, Abdolalizadeh J, Yousefi M, Ahmadi M, et al. Production and purification of a polyclonal antibody against purified mouse igg $2 \mathrm{~b}$ in rabbits towards designing mouse monoclonal isotyping kits. Adv Pharm Bull. 2015; 5(1).

38. Niedergang F, Hémar A, Hewitt CR, Owen MJ, Dautry-Varsat A, Alcover A. The staphylococcus aureus enterotoxin B superantigen induces specific $\mathrm{T}$ cell receptor down-regulation by increasing its internalization. J Biol Chem. 1995; 270: 12839-45.

39. Irina V, Pinchuk Ellen J. Beswick and victor e. reyes. Staphylococcal Enterotoxins. Toxins. 2010; 2(8): 2177-97.
40. Sadeghi J, Alizadeh N, Ahangar Oskouei M, Laghusi D, Savadi Oskouei D, Nikanfar M, et al. Frequency of superantigen encoding genes of Staphylococcus aureus isolates collected from multiple sclerosis (MS) patients and nasal carriers. Microb Pathog. 2019; 127: 316-9.

41. Torres BA, Kominsky S, Perrin GQ, Hobeika AC, Johnson HM. Superantigens: the good, the bad, and the ugly. Exp Biol Med. 2001; 226(3): 164-76.

42. Wang X, Wang BR, Zhang XJ, Duan XL, Guo X, Ju $\mathrm{G}$. Fos expression in the rat brain after intraperitoneal injection of Staphylococcus enterotoxin B and the effect of vagotomy. Neurochem. Res. 2004; 29: 1667-74.

43. Popoff MR, Poulain B. Bacterial toxins and the nervous system: neurotoxins and multipotential toxins interacting with neuronal cells. Toxins (Basel). 2010; 2(4): 683-737. 